\title{
Profissionalidade e desenvolvimento profissional docente no ensino tecnológico no Brasil
}

\section{Professionalism and teacher professional development in technological education in Brazil}

\author{
Nadja Maria de Lima Costa*, Ana Maria Costa e Silva** \\ *Instituto Federal de Educação, Ciência e Tecnologia do Rio Grande do Norte \\ ** Instituto de Educação, CECS, Universidade do Minho
}

\begin{abstract}
Resumo
Abordamos questões relativas à profissionalidade e desenvolvimento profissional docente, enquadradas numa investigação realizada no âmbito do doutoramento em Ciências da Educação, na Universidade do Minho. Um dos objetivos deste estudo centrou-se na análise das relações entre identidade e desenvolvimento profissional de professores, tendo como amostra os docentes de um Curso de Tecnologia em Construção de Edifícios (CSTCE), de um instituto superior tecnológico do Brasil. Os resultados mostram que a profissionalidade e o desenvolvimento profissional dos docentes no CSTCE, se relaciona com a docência do ensino superior, em âmbitos individuais e coletivos, considerando as dimensões pessoais, profissionais e organizacionais.

Palavras-chave: profissionalidade docente, desenvolvimento profissional, educação superior.
\end{abstract}

\section{Abstract}

We discuss issues related to professionalism and teacher professional development, framed in a research carried out within the $\mathrm{PhD}$ in Educational Sciences, at the University of Minho. One of the objectives of this study was centered in the analysis of the relationship between identity and professional development of teachers, having as a sample the teachers of a Technology Course in Construction of Buildings (CSTCE) of a higher technological institute in Brazil. The results show that the professionalism and professional development of teachers in the CSTCE are related to higher education teaching in individual and collective settings, considering the personal, professional and organizational dimensions.

Keywords: Professionalism, professional development, higher education.

\section{Introdução}

A discussão acerca da profissionalidade e desenvolvimento profissional docente ocupa um relevante espaço no meio académico e profissional do ensino superior. Apresenta-se como ponto central, no tocante aos aspectos da identidade e do desenvolvimento curricular, em qualquer nível de ensino. Atualmente, nas produções académicas sobre a educação superior, tais discussões revelam a atenção dada à formação e ao desenvolvimento profissional dos docentes. Envolvem múltiplos aspetos da docência tendo em vista as novas exigências e os desafios impostos e, sobretudo, ressaltam aspectos pedagógicos que se consideram fundamentais no processo de ensino e aprendizagem deste nível educativo.

De acordo com Leite e Ramos (2012), o cenário pedagógico da educação superior no início do século XXI, foi marcado por uma mudança de foco na atuação docente, no sentido de humanizar a formação ou humanizar a cultura científica, tendo focagem no sujeito aluno e no processo de ensino e de aprendizagem deste. Tais marcos estão postulados na Declaração Mundial sobre a Educação Superior no século XXI (UNESCO, 1998), assim como nas finalidades presentes na Declaração do Processo de Bolonha, de 1999.

Na perspectiva de Gatti (2008), a preocupação com a formação de professores entrou na pauta mundial, na última década, graças à conjunção de dois movimentos: de um lado, as pressões do mundo do trabalho, estruturado em novas condições, baseado num modelo informatizado e valorado no conhecimento; de outro lado, situa-se a constatação, pelos sistemas governamentais, dos precários desempenhos escolares de grandes parcelas da população. Essa realidade se configura em uma contradição e um impasse. Como solução, políticas públicas e ações políticas são implementadas na direção de reformas curriculares e de mudanças na formação dos docentes, enquanto formadores das novas gerações.

Tais encaminhamentos político-pedagógicos têm relação com novas concepções da docência e de formação para tal atividade. Assume uma abordagem vinculada à criação de condições asseguradoras de aprendizagens, tanto dos estudantes, quanto dos professores, bem como da utilidade social dos saberes. Nesta acepção, a docência implica um modo de preparar o sujeito para a aprendizagem autônoma, porém acompanhada e baseada numa relação acolhedora e inclusiva, numa lógica de compreensão, exigências e apoio para a aprendizagem (Leite, 2006). Especificamente, no campo da docência da educação superior, tais definições se alinham à construção de espaços de diálogos entre a cultura humanística e a cultura científica e tendem a se estreitarem, 
despontando-se para uma (re)contextualização de fazeres e saberes nesta atuação (Leite \& Ramos, 2012).

Neste cenário, Almeida e Pimenta (2009) destacam que a formação dos docentes do ensino superior e a preocupação com a qualidade na condução dos processos de ensino e de aprendizagem, passam a ter uma maior importância na perspectiva de ações voltadas a promover mudanças nas práticas pedagógicas, constituindo desafios políticos e pedagógicos. Tal inquietação implica políticas administrativas nas instituições e ações reflexivas, tanto em sala de aula, nas vivências com o conhecimento e na articulação entre teoria e prática, quanto nas relações interpessoais e nos processos de mediação pedagógica.

Refletir sobre profissionalidade e desenvolvimento profissional docente se configura em um consenso, compreendido de inúmeras possibilidades de "construção do docente" (Almeida, 2012, p. 70). Para a autora, a construção da identidade docente, perpassa por um leito de dimensões e se compõe de vários elementos da profissionalidade, articulados permanentemente e em sintonia com o desenvolvimento profissional. Tal compreensão da tridimensionalidade da docência significa reconhecer que esta se estrutura na construção da identidade do professor, no domínio dos elementos teóricos e contextuais da sua prática (pedagógicos) e na propriedade do campo científico (Almeida, 2012).

No âmbito de um estudo mais amplo sobre (re)construção identitária de professores do ensino superior tecnológico num específico curso de Tecnologia em Construção de Edifícios (CSTCE), apresentaremos, um recorte de parte desta investigação. Tal abordagem advém de uma investigação qualitativa, orientada pelos aportes teóricos da fenomenologia e da dialética, utilizando-se a metodologia compreensiva, a partir de narrativas escritas e entrevista em grupo focal. O percurso metodológico visa compreender percepções e reflexões dos sujeitos, tendo em vista a especificidade da temática: tratar da "identidade de si e identidade para o outro" (Dubar, 1997; Silva, 2005; Bauman, 2001; e outros).

Nesse sentido, esta análise nos remete às questões centrais referentes a como os professores do CSTCE constroem as suas identidades profissionais com base em aspectos da profissionalidade e do desenvolvimento profissional docente e o que caracteriza a identidade profissional dos docentes do CSTCE. O presente recorte nos aproxima das questões antes enunciadas e os pontos a seguir se constituem parte dos resultados da investigação realizada.

\section{Especificidades da profissionalidade docente no CSTCE}

Para autores como Almeida e Pimenta (2009), Roldão (2005) e Tardif (2002), a profissionalidade docente é composta por um conjunto de saberes que distinguem a especificidade da atividade profissional docente. Refere-se a um processo ativo, incidindo numa construção individual e coletiva que ganha materialidade nos espaços de trabalho e traz, na práxis docente e nas relações dos professores com seus diferentes interlocutores, a afirmação ou a negação da profissão.

Nessa perspectiva, Tardif (2002) e Roldão (2005) defendem que os saberes estão relacionados ao cotidiano das situações de trabalho e postulam que tais saberes são construídos a partir de categorias relacionadas com a trajetória percorrida pelos professores ao construírem saberes que emanam da prática, das vivências e relações estabelecidas no trabalho. Num movimento cíclico, são reelaborados e retornam à prática em sua dinâmica profissional cotidiana.

Roldão (2005) elabora quatro descritores ou caracterizadores da profissionalidade docente, fundamentados na literatura da sociologia das profissões. Dependem de fatores histórico-sociais que estão na base da reprodução da atividade docente, de modo intra e extra comunidade dos praticantes da profissão. São representações sociais confrontadas com as práticas de ensino nos âmbitos de poder, saber próprio, clareza da função social desempenhada e sentido de comunidade profissional (Roldão, 2005).

Para conhecimento e análise, vejamos alguns destaques das narrativas escritas e dos grupos focais, que os professores evidenciam relativos ao primeiro descritor da profissionalidade docente: o reconhecimento social da especificidade da função associada à atividade (Roldão, 2005):

\section{Percepções sobre o reconhecimento social da função}

\begin{tabular}{|c|c|}
\hline $\begin{array}{l}\text { Nesse aspecto, nosso corpo } \\
\text { docente aqui é muito rico, } \\
\text { pois tem pessoas com } \\
\text { múltiplas formações como, } \\
\text { por exemplo, aqui eu } \\
\text { conheço o professor } \\
\text { [Nome]... A gente tem } \\
\text { formação: eu sou da } \\
\text { matemática, ele da física, ali } \\
\text { é da engenharia e é } \\
\text { licenciado em tal disciplina. } \\
\text { A gente tem formação pra } \\
\text { ser professor também. (D-7, } \\
\text { Grupo Focal, maio/2015). }\end{array}$ & $\begin{array}{l}\text { Procuro me atualizar dentro } \\
\text { de todas as áreas que atuo } \\
\text { como docente. Faço isso } \\
\text { porque respeito a profissão } \\
\text { que abracei e aos alunos do } \\
\text { técnico (D-04, narrativa, } \\
\text { dezembro/2014). } \\
\text { Desejo poder continuar } \\
\text { compatibilizando minhas } \\
\text { atividades como engenheiro } \\
\text { e como docente em } \\
\text { disciplinas da área, [...] } \\
\text { (D-13, narrativa, } \\
\text { dezembro/2014). }\end{array}$ \\
\hline
\end{tabular}

Tais percepções revelam reconhecimento da especificidade da função docente, expressam a identificação com a profissão e com o exercício dessa função na instituição a que pertencem, onde situam particularidades da docência na educação profissional. Explicitam a compreensão individual e coletiva da valorização profissional em uma instituição que tem tradição histórica e reconhecimento social. É também destacada a necessidade de formação específica em determinadas disciplinas/áreas, inclusive, ressaltando outras possibilidades de aquisição de saberes da experiência (Tardif, 2002).

Nas declarações dos professores são evidenciados aspetos da identidade profissional abordados por Dubar (1997), Silva (2005, 2003) e Silva e Aparício (2015), 
onde se destacam os valores, os sentimentos, o reconhecimento na identidade de si e identidade para o outro, entre outras percepções individuais e coletivas. Em uma compreensão geral das percepções dos professores, ficam evidenciados os sentimentos de pertença à profisssão docente e a inscrição sócio-histórica dessa atuação profíssional na instituição onde atuam.

Em relação ao segundo descritor da profissionalidade docente, 0 saber específico indispensável ao desenvolvimento da atividade e sua natureza (Roldão, 2005), ao construirmos a reflexão sobre necessidades de conhecimentos específicos para a atuação docente no CSTCE (aspecto abordado tanto nas narrativas como nos grupos focais), os participantes revelam duas diferentes percepções.

Uma parte expressa a representação frequente entre os professores do ensino superior, uma prática difundida culturalmente e pautada na crença de que os conhecimentos para a docência estão, essencialmente, nos conteúdos científicos específicos da disciplina. Por outro lado, reforçando a complexidade do trabalho docente, eminentemente um fazer coletivo e particularizado, bem como intencional e politizado, alguns reconhecem a necessidade dos conhecimentos pedagógicos. Nesta última acepção, há os que perfilham que, para ser professor, se faz necessário uma formação específica, conforme defendem vários estudiosos desta temática. Assim, realçamos os posicionamentos dos professores a partir das seguintes declarações:

\section{Percepções sobre o saber específico indispensável à atividade e sua natureza}

\begin{tabular}{|c|c|}
\hline $\begin{array}{l}\text { Reconhecimento dos saberes } \\
\text { pedagógicos }\end{array}$ & $\begin{array}{l}\text { Desconhecimento dos } \\
\text { saberes pedagógicos }\end{array}$ \\
\hline $\begin{array}{l}\text { Mas, pelo menos tentar dar essa } \\
\text { abordagem para saber onde o } \\
\text { professor tem maiores } \\
\text { dificuldades, pelo menos, que } \\
\text { fossem apresentadas. É uma } \\
\text { maneira até dele, superar isso. } \\
\text { Eu acho que seria bem } \\
\text { interessante. Eu não tenho } \\
\text { como me avaliar, eu não tenho, } \\
\text { eu não sei. E olhe que assim, a } \\
\text { gente sempre está tentando ver } \\
\text { o lado crítico da coisa (D-8, } \\
\text { grupo focal, maio/2015). }\end{array}$ & $\begin{array}{l}\text { Como já conclui o } \\
\text { doutorado, pelo menos até o } \\
\text { presente momento, não vejo } \\
\text { necessidade de atualização } \\
\text { ou preparação de algum } \\
\text { curso para atuar como } \\
\text { docente (D-9, narrativas, } \\
\text { dezembro/2014). }\end{array}$ \\
\hline $\begin{array}{l}\text { Eu tenho um estilo de } \\
\text { aprendizagem e eu me } \\
\text { identifiquei com alguns estilos } \\
\text { de ensino dos professores da } \\
\text { época. Agora, o que eu não } \\
\text { tenho absoluta certeza é se o } \\
\text { pessoal dessa geração de agora, } \\
\text { tem o estilo de aprendizagem ou } \\
\text { aprendem com o modo que eu } \\
\text { ensino. E, se eu estou usando o } \\
\text { modo e técnica adequada (D-1, } \\
\text { grupo focal, maio/2015). }\end{array}$ & $\begin{array}{l}\text { Considero que todo o } \\
\text { conjunto da minha } \\
\text { formação acadêmica me } \\
\text { propiciou adquirir bases } \\
\text { teóricas e metodológicas } \\
\text { para atuar como docente do } \\
\text { CSTEC (D-3, narrativas, } \\
\text { dezembro/2014). }\end{array}$ \\
\hline
\end{tabular}

Alguns dos professores explicitam necessidades de conhecimentos sobre o processo de ensino e de aprendizagem. Referem-se a lacunas em conteúdos específicos, escolhas metodológicas e estratégias pedagógicas, bem como evidenciam a importância do diálogo com os estudantes, enquanto sujeitos do processo. Também a literatura sobre a temática evidencia que o conhecimento das estratégias metodológicas no campo didático-pedagógico é aspecto categórico da função docente, conforme afirmam Roldão $(2005,2007)$ e Zabalza (2004), entre outros. Sem dúvida, um saber específico e indispensável à função docente.

A partir da negação dos saberes pedagógicos, vivencia-se uma docência circunstanciada por frágil sustentação teórica e prática no campo pedagógico-didático. Em diversos estudos encontramos críticas a tal posição pragmática de negação e ausência dos conhecimentos pedagógicos na formação e atuação profissional docente (Zabalza, 2004; Roldão, 2005; Cunha, 2007).

No que se refere ao terceiro descritor da profissionalidade docente, o poder de decisão e autonomia sobre o trabalho desenvolvido (Roldão, 2005), consideramos os excertos a seguir bastante representativos desta definição:

Percepções sobre o poder de decisão e autonomia

Motivação para fazer essas discussões tem, sim. [...]

Vislumbro aplicação, tipo assim, vamos diagnosticar, vamos ver, vamos verificar o problema, aí chegamos a tal conclusão. Mas, eu não vejo que a solução encontrada aqui, qualquer que seja ela, eu não vejo que a gente tenha autonomia em aplicar, não (D-9, grupo focal, maio/2015).

Nem deixam eu chegar na porta do MEC. A desculpa é essa, toda vez que a gente levanta essa questão, aí... Não vou colocar $100 \%$ para não estar exagerando, vou colocar uns $90 \%$ do grupo, concordam em dá um up para engenharia plena... (D-4, grupo focal, maio/2015).

Fonte: grupo focal sobre identidade docente no CSTCE

Alguns professores demonstram que não constroem/construíram seu(s) currículo(s) com autonomia plena. Relatam a participação e o controle do órgão de gestão central, o Ministério da Educação. Revelam que, por ocasião da implantação do modelo de cursos superiores de tecnologia (CST), prevaleceu a imposição, sem ocorrer a escuta à comunidade educativa ou à sociedade do entorno, apenas, houve o convencimento unilateral. Tal perspectiva na educação profissional é situada por Brandão (2009) e Lima (2005), ao analisarem as políticas de expansão da educação superior na década de 1990, sob a lógica da diversificação e flexibilização, apontam crítica específica aos CST, considerados como mais uma dualidade na educação brasileira por seu aspecto aligeirado e mercadológico (Ciavatta, 2012).

Em geral, as percepções evidenciam a tese de que a tomada de posição nas questões curriculares tem sido 
sempre uma decisão política de um coletivo em articulação com outros entes ou setores sociais. É próprio da natureza do currículo ser um campo de disputas e de permanentes questionamentos sobre o conhecimento, motivados pelas dinâmicas culturais, políticas e educacionais, porém, sustentado em bases emancipatórias e comprometido com a formação ética e cidadã (Pacheco, 2006; Morgado, 2005). Nessa perspectiva, Apple (1995) alerta também para que as escolas não se conformem à postura de legitimar o conhecimento enquanto mercadoria.

Conforme refere Roldão (2005), a mencionada limitação de poder sobre a matéria do trabalho docente (por exemplo, a negação nas decisões curriculares), dificulta a organização de coletivos autônomos dos profissionais do ensino com a finalidade de defender e constituir o seu saber próprio. A autora discute implicações desencadeadas pela falta de poder ou autonomia em decisões próprias da atividade docente, bem como destaca a interferência dessa ausência de autonomia no saber profissional e na profissionalidade como um todo. Tomando por base as contribuições de Roldão (2005) e de vários outros estudos sobre profissionalidade docente, elaboramos o conceito de ciclo de fragilização da profissionalidade e da profissão docente.

No que se refere ao quarto descritor de profissionalidade docente, a pertença a um corpo coletivo que compartilha, regula e defende o saber que o legitima (Roldão, 2005), destacamos trechos de falas dos participantes como expressões bastante significativas e reveladoras do sentimento de pertença a um grupo ou a um coletivo de profissionais:

Percepções sobre sentimento de pertença a um grupo de profissionais
Eu vejo um ponto positivo, eu não diria no [Nome $\}$ inteiro. É nessa diretoria, é o grupo, o grupo é pequeno e ele é harmônico. Eu vejo colegas de outras diretorias comentarem problemas e a gente aqui... Eu não vejo isso aqui. Aqui é um grupo que se entende, [...] (D-1, grupo focal, maio/2015).

[...] mas a gente ainda tem um diálogo muito estanque, como de resto, também acontece nos cursos técnicos. Mas digamos dentro do Curso de Tecnologia, a gente ainda dialoga pouco, nível a nível, dos seis períodos ou no mesmo período. A gente ainda dialoga pouco, a gente acaba sabendo pouco aquilo que o aluno sabe mais do que a gente (D-7, grupo focal, maio/2015).

Fonte: grupo focal sobre identidade docente no CSTCE

Nos trechos, os professores revelam que têm "o grupo", ou os seus pares, como referência para as decisões. Reportam-se às reuniões entre colegas, admitindo que embora sejam poucos, se configuram em um grupo unido que se mantém em harmonia. Consideram este coletivo como espaço para discutirem as questões inerentes ao fazer docente e às questões do trabalho realizado na Diretoria. Porém, apontam que o diálogo ainda é insuficiente quanto ao planejamento, à organização das práticas e aos objetivos do processo de ensino e aprendizagem. Afirmam ainda, que o trabalho desenvolvido poderia ser melhor. Evidenciam aspectos positivos que trazem unidade ao grupo e revelam, portanto, que possuem um espaço profissional instituído como uma referência, constituído num certo habitus do coletivo (Bourdieu, 2003).

Contudo, destaca-se a expectativa de diálogos acerca da organização pedagógica do currículo, tanto nas atuações do CSTCE quanto nos demais cursos de nível técnico, onde também atuam. Fazem uma crítica à ausência de práticas interdisciplinares no desenvolvimento do curso, ressentindo-se com a falta de aproximações nas metodologias e objetivos das diversas disciplinas estruturantes do currículo. Mormente, a perspectiva interdisciplinar é bastante debatida entre os pesquisadores da área de currículo e das práticas pedagógicas em todos os níveis educacionais. Por sua vez, presenciamos um considerável destaque desta temática no contexto do ensino superior (Zabalza, 2004; Masetto, 1998; Braslavsky, 1999).

\section{Questões de desenvolvimento profissional docente no CSTCE}

$\mathrm{Na}$ atual conjuntura, a compreensão de desenvolvimento profissional docente se estabelece sob um conceito diferenciado da ideia de formação baseada em cursos desvinculados do cotidiano e das práticas profissionais. Assume múltiplas significações, envolvendo diferentes processos e atividades que visam problematizar a realidade e transformar práticas escolares, bem como construir novos contextos da docência, primando pela emancipação e autonomia dos professores.

É de suma importância demarcar o conceito de desenvolvimento profissional docente perspectivado neste estudo a partir de autores como, Ramos (2010), Day (2004), Flores (2015), dentre outros. Seus estudos discutem a profissão e o desenvolvimento profissional docente, alguns deles focando a urgente reconceitualização da docência do ensino superior.

Nesta temática, os resultados da investigação apresentam relevantes necessidades de conhecimentos específicos tais como: didático-pedagógicos; trabalho coletivo e de diálogo interdisciplinar. Referem o complexo perfil dos estudantes do CSTCE e expectativas e interesses de revisão curricular, voltada para uma oferta de curso superior mais atrativo no contexto socioeconômico, onde se insere a instituição ofertante. São questões que remetem a profícuos estudos curriculares e à elaboração de propostas pedagógicas, configurando-se, assim, em mais demandas formativas.

$\mathrm{O}$ estudo permitiu também identificar outros aspetos relacionados com o que anteriormente foi referido. Salientam-se como exemplo, os requisitos de ingresso na carreira docente, as condições de trabalho em uma carreira profissional híbrida, tendo a educação básica e todas suas demandas de formação técnica de jovens adolescentes e, a educação tecnológica, com todas as exigências da educação superior. Portanto, discutir a profissionalidade docente e o desenvolvimento profissional no CSTCE, implica problematizar a 
docência do ensino superior, em âmbitos individuais e coletivos, considerando as dimensões pessoais, profissionais e organizacionais. Ou seja, significa iniciar e retornar às questões identitárias, às necessidades formativas e ao conhecimento dos atributos da docência como uma profissão de interações humanas.

\section{Considerações finais}

Com base na revisão da literatura e nas percepções do grupo de professores coautores da investigação, reafirmamos a intrínseca relação entre identidade, condições materiais, saberes da docência e perspectivas do desenvolvimento profissional dos docentes no CSTCE. Admitimos, portanto, a premissa de que o trabalho modifica o trabalhador e a sua identidade, e esta, por sua vez, vai modificando, com o passar do tempo, o seu saber trabalhar (Raymond \& Tardif, 2000).

O estudo aborda questões específicas de identidade e atuação docente no ensino tecnológico, suas peculiaridades e idiossincrasias de uma educação superior, considerada por alguns investigadores, como mais uma proposta de dualidade na educação brasileira. Indica, sobretudo, caminhos de uma busca ativa para a superação de dificuldades pedagógicas, rumo à construção de propostas educativas à luz de princípios da qualidade social na educação superior tecnológica.

Em síntese, traduz um desafio para conceituar a profissionalidade docente no CSTCE. Além disso, pontua a atuação profissional docente num curso espececífico do Ensino Superior Tecnológico. Os descritores utilizados apresentam diversos matizes de um fazer profissional que é específico, histórico e contextualizado.

\section{Referências}

Almeida, M. I. \& Pimenta, S. G. (2009). Pedagogia Universitária: valorizando o ensino e a docência na Universidade de São Paulo. São Paulo: Edusp, pp 13-38.

Almeida, M. I. D. (2012). Formação do professor do ensino superior: desafios e políticas institucionais. São Paulo: Cortez.

Apple, M. W. (1995). Repensando Ideologia e Currículo. In A. F. Moreira \& T. T. Silva (Orgs). Currículo, cultura e sociedade. São Paulo: Cortez.

Bauman, Z. (2001). Modernidade líquida. Rio de Janeiro: Jorge Zahar.

Bourdieu, P. (2003). A Dominação Masculina. Rio de Janeiro: Editora Bertrand Brasil.

Brandão, M. (2009). Metamorfose dos Cursos Superiores de Tecnologia no Brasil: política de acesso ao ensino superior em um Estado burguês. Tese de doutorado. Universidade Federal Fluminense, Niterói, RJ, Brasil.

Braslavsky, C. (1999). Bases, orientaciones y criterios para el diseño de programas de formación de profesores. Revista Iberoamericana de Educación, 19, pp. 1-28.

Ciavatta, M. (2012). Gaudêncio Frigotto - Um intelectual crítico nos pequenos e nos grandes embates. Autêntica.
Cunha, M. I. (2007). O lugar da formação do professor universitário: A condição profissional em questão. In M. I. Cunha (Org.). Reflexões e práticas em pedagogia universitária, pp. 11-26. Campinas/SP: Papirus.

Day, C. (2004). A paixão pelo ensino. Porto: Porto Editora.

Dubar, C. (1997). A socialização. Construção das identidades sociais e profissionais. Porto: Porto Editora.

Flores, M. A. (2015). Formação docente e identidade profissional: tensões e (des) continuidades. Educação, 38(1), pp.138-146.

Gatti, B. A. (2008). Análise das políticas públicas para formação continuada no Brasil, na última década. Revista Brasileira de Educação, 13(37), 57-70.

Leite, C. (2006). Percursos e tendências recentes da formação de professores em Portugal. Educação, 28(3).

Leite, C., \& Ramos, K. (2012). Formação para a docência universitária: uma reflexão sobre o desafio de humanizar a cultura científica. Revista Portuguesa de Educação, 25(1), pp. 07-27.

Lima, D. \& Filho, L. (2005, julho/dezembro, 02). A universidade tecnológica e sua relação com o ensino médio e a educação profissional: discutindo a identidade e o futuro dos CEFETs. 23(2), pp. 349-380.

Masetto, M. T. (1998). Professor universitário: um profissional da educação na atividade docente. Campinas-SP: Papirus.

Morgado, J. C. (2005). Currículo e profissionalidade docente. Porto Editora.

Pacheco, J. A. (2006). Currículo: teoria e práxis ( $3^{\mathrm{a}}$ ed.). Porto: Porto Editora.

Ramos, K. M. C. (2010). Reconfigurar a profissionalidade docente universitária: um olhar sobre as atualizações da atualização pedagógico-didática. U.Porto Editorial: Porto.

Roldão, M. C. (2005). Profissionalidade docente em análise: especificidades dos ensinos superior e não superior. Nuances: estudos sobre educação, 12(13), pp. 105-126.

Silva, A. M. C. (2003). Formação, Percursos e Identidades. Coimbra: Quarteto Editora.

Silva, A. M. C. (2005). Formação e Construção de Identidade(s). Um Estudo de Caso centrado numa Equipa Multidisciplinar. Braga: Universidade do Minho. Tese de Doutoramento (policopiada).

Silva, A. M. C \& Aparicio, M. (eds.) (2015). International Handbook of Professional Identities. USA: Scientific \& Academic Publishing.

Tardif, M. (2002). Saberes docentes e formação profissional. $4^{\mathrm{a}}$ Ed. Rio de Janeiro: Vozes.

Tardif, M., \& Raymond, D. (2000). Saberes, tempo e aprendizagem do trabalho no magistério. Educação \& Sociedade, 21(73), 209-244.

UNESCO (1998). Declaración mundial sobre la Educación Superior en siglo XXI: Visión y acción. Recuperado em 6 de Agosto de 2006: http://www.unesco.org/education/educprog/wche/ declaration_spa.htm 
NADJA, COSTA

Zabalza, M. A. (2004). O ensino universitário seu cenário e seus protagonistas. Porto Alegre: Artmed. 